\title{
AVALIAÇÃO DA PERFUSÃO TECIDUAL NO CHOQUE
}

\author{
TISSUE PERFUSION ASSESMENT IN SHOCK
}

\author{
Eliézer Silva ${ }^{1}$; Alejandra Gallardo Garrido² \& Murillo S. C. Assunção²
}

\begin{abstract}
${ }^{1}$ Mestre em Medicina Interna - Universidade Federal de Santa Catarina. Doutor em Medicina - Universidade Federal de São Paulo.Coordenador do Grupo de Suporte Hemodinâmico do Centro de Terapia Intensiva, do Hospital Israelita Albert Einstein. Médico Pesquisador da Disciplina de Doenças Infecciosas e Parasitárias da Universidade Federal de São Paulo. Professor Titular da

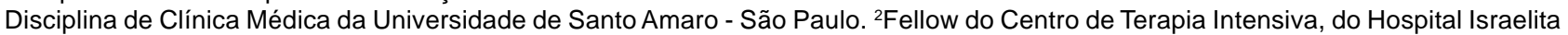
Albert Einstein.

CorResPondÊnCIA: Eliézer Silva. Avenida Moaci, 534, Apto 54-B. Moema - São Paulo - SP. CEP 04083-001 - Fax:0xx1137469411 e-mail:eliezer@einstein.br
\end{abstract}

SILVA E; GARRIDO AG \& ASSUNÇÃO MSC. Avaliação da perfusão tecidual no choque. Medicina, Ribeirão Preto, 34: 27-35, jan./mar.2001.

RESUMO: Apesar das diversas inovações tecnológicas e do melhor entendimento fisiopatológico dos estados de choque, esta condição permanece com elevada taxa de morbimortalidade. Uma das explicações mais aceitas para a taxa elevada é o desenvolvimento da síndrome de disfunção de múltiplos órgãos (SDMO), secundária à hipoperfusão tecidual persistente. Assim, é evidente a importância da avaliação da perfusão tecidual em tais quadros, bem como possíveis interferências terapêuticas a partir da avaliação.

Nesta revisão, são abordadas noções básicas sobre a monitorização clínica e laboratorial da perfusão tecidual no choque, incluindo transporte de $\mathrm{O}_{2}$, consumo e taxa de extração de $\mathrm{O}_{2}$, saturação venosa mista de $\mathrm{O}_{2}$, lactato e gradiente gastroarterial de $\mathrm{CO}_{2}$. Tais dados são fundamentais para a correta interpretação e melhor intervenção terapêutica, visando adequar o desequilíbrio presente entre oferta/consumo de $\mathrm{O}_{2}$ e, desta forma, interromper a série de eventos fisiopatológicos que resulta em SDMO e, em muitas condições, em morte.

Nesse contexto, algumas metas devem ser alcançadas durante a ressuscitação de pacientes com síndrome do choque, a saber: pressão arterial média > $65 \mathrm{mmHg}$; diurese ${ }^{3} 1 \mathrm{ml} / \mathrm{kg} / \mathrm{hora}$; débito cardíaco suficiente para manter uma $\mathrm{SvO}_{2}>65 \%$; lactato sérico $<2 \mathrm{mmol} / \mathrm{L}$, destacando que, mesmo quando normalizadas as variáveis sistêmicas de oxigenação, graves distúrbios perfusionais regionais ainda podem existir, sendo necessário recorrer à monitorização regional através da avaliação do $\mathrm{pCO}_{2}$-gap.

UNITERMOS: Choque. Perfusão Tecidual. Tonometria. Lactato. Transferência de Oxigênio.

\section{INTRODUÇÃO}

Choque é caracterizado por uma redução, absoluta ou relativa, da oferta de oxigênio aos tecidos, secundário a graves distúrbios perfusionais, desencadeando um metabolismo anaeróbio. O evento final do processo é a disfunção orgânica, principal causa de morte nesta população.

A avaliação da perfusão tecidual, em pacientes com diagnóstico de choque, vem incorporando novos princípios fisiopatológicos, uma vez que choque não pode ser entendido apenas por hipotensão arterial, e, sim, por um estado de inadequada oxigenação celu$\operatorname{lar}^{(1)}$. Desta forma ,níveis pressóricos normais não garantem adequada perfusão tecidual.

Perfusão tecidual pode ser conceituada como o produto do fluxo capilar pelo conteúdo de nutrientes e de oxigênio oferecidos aos tecidos. Portanto, duas variáveis são importantes: fluxo e conteúdo de oxigênio. Fluxo pode ser entendido como débito cardíaco e sua 
distribuição, enquanto que a análise do conteúdo leva em consideração a concentração sérica de hemoglobina, a saturação e a pressão parcial de oxigênio arterial.

Outra consideração diz respeito à necessidade de avaliar a perfusão tecidual através de variáveis sistêmicas e regionais, uma vez que existe uma distribuição heterogênea de fluxo durante a instalação e a fase de ressuscitação do paciente em choque. Assim, o paciente deve ser avaliado continuamente e a interpretação das variáveis obedece a um racional clínico, que prevalecerá inicialmente, e a um racional fisiológico e laboratorial, que completará o entendimento mais pormenorizado da perfusão tecidual.

Com tais informações, este capítulo visa rever alguns conceitos fisiológicos e fisiopatológicos para auxiliar o clínico na avaliação do paciente com hipoperfusão tecidual através de variáveis clínicas e laboratoriais.

\section{FLUXO SANGÜÍNEO E TRANSPORTE DE OXIGÊNIO $\left(\mathrm{TO}_{2}\right)$}

A manutenção da oferta de oxigênio às células, atendendo à demanda metabólica, ou seja, requerimento energético, é uma função crucial do sistema cardiorrespiratório. Sob condições normais, a oferta de oxigênio às células é controlada pela taxa metabólica celular, processo denominado "oferta direcionada pela demanda”. Em várias condições patológicas, o sistema cardiorrespiratório pode ser incapaz de satisfazer a demanda metabólica dos tecidos ${ }^{(2)}$. Portanto, nessas condições, a manipulação das variáveis que interferem no transporte sistêmico de oxigênio $\left(\mathrm{TO}_{2}\right)$, é uma freqüente intervenção direcionada aos pacientes gravemente enfermos, visando adequar o $\mathrm{TO}_{2}$ à demanda metabólica $^{(1)}$.

Pode-se dizer que o $\mathrm{TO}_{2}$ se inicia quando o oxigênio é captado da atmosfera, difundindo-se do espaço alveolar para o sangue capilar, onde é transportado ligado à hemoglobina e, em pequena parte, dissolvido no plasma. Então, através do débito cardíaco (DC), o fluxo sangüíneo é distribuído na circulação sistêmica e, posteriormente, na micro-circulação. Finalmente, o oxigênio é liberado da hemoglobina e se difunde do espaço intravascular para o espaço intracelular, onde é utilizado para manter as funções vitais em nível celular, o que se traduz na obtenção de energia, através do ciclo de Krebs e da cadeia respiratória ${ }^{(3)}$. Essas etapas podem ser interrompidas em qualquer nível, ou seja, pode ocorrer diminuição da oxigenação sangüínea, di- minuição da taxa de hemoglobina ou diminuição do DC. O perfeito entendimento dos processos fisiopatológicos, que podem aí interagir, é fundamental para a correta interpretação clínica e laboratorial das manifestações apresentadas pelo paciente, com conseqüente adequada intervenção terapêutica. Isso seria uma maneira simplista de descrevermos o $\mathrm{TO}_{2}$, sendo que o mesmo é o produto do DC e do conteúdo arterial de $\mathrm{O}_{2}$ $\left(\mathrm{CaO}_{2}\right)$ como denotado na equação de Fick:

$$
\begin{gathered}
\mathrm{TO}_{2}=\mathrm{CaO}_{2} \times \mathrm{DC} \times k \text { onde, } \\
\mathrm{CaO}_{2}=\left(\mathrm{Hb} \times \mathrm{SaO}_{2} \times 1,34\right)+\left(0,003 \times \mathrm{PaO}_{2}\right) \\
k \text { - constante } \mathrm{Hb}-\text { hemoglobina } \mathrm{PaO}_{2} \text { - pres- }
\end{gathered}
$$
são parcial de oxigênio; 1,34 - quantidade de $\mathrm{O}_{2}$ que 1,0g de $\mathrm{Hb}$ consegue carrear

Embora o $\mathrm{TO}_{2}$ seja manipulado na tentativa de adequar o desequilíbrio oferta/consumo de $\mathrm{O}_{2}$, o que, de fato, chega à célula é denominado oferta de $\mathrm{O}_{2}$ $\left(\mathrm{DO}_{2}\right)$, uma vez que a presença de shunts anatômicos ou virtuais podem desviar o oxigênio transportado aos tecidos. Consumo de oxigênio $\left(\mathrm{VO}_{2}\right)$ é a variável que melhor reflete demanda metabólica, e taxa de extração de $\mathrm{O}_{2}\left(\mathrm{TEO}_{2}\right)$ é a relação entre $\mathrm{DO}_{2}$ e $\mathrm{VO}_{2} \cdot{ }^{(2,4)}$

A $\mathrm{TEO}_{2}$ pode estar diminuída nos casos em que há um aumento do fluxo sangüíneo tecidual e extração celular de $\mathrm{O}_{2}$, reduzida, ou pode estar aumentada, nos casos em que o sangue passa lentamente e a célula extrai mais $\mathrm{O}_{2}$. A $\mathrm{TEO}_{2}$ segue a seguinte equação:

$$
\mathrm{TEO}_{2}(\%)=\frac{\mathrm{DO}_{2}-\mathrm{VO}_{2}}{\mathrm{DO}_{2}} \times 100
$$

Em condições normais, o $\mathrm{VO}_{2}$ é independente da $\mathrm{DO}_{2}$, e é determinado pela demanda metabólica dos tecidos. À medida que $\mathrm{a} \mathrm{DO}_{2}$ diminui, os tecidos se adaptam através do aumento da $\mathrm{TEO}_{2}$ para manter relativamente estável o consumo em qualquer nível de $\mathrm{DO}_{2}$, até um determinado ponto ( $\mathrm{DO}_{2}$ crítica), a partir do qual reduções maiores da oferta ocasionam reduções proporcionais no $\mathrm{VO}_{2}$ (dependência fisiológica da oferta de $\mathrm{O}_{2}$ ), surgindo, então, acidose láctica ${ }^{(2)}$. Figura 1.

Entretanto, em condições patológicas (sepse, insuficiência respiratória, etc.), há um prejuízo na capacidade tecidual de extração de $\mathrm{O}_{2}$. Nessas situações, o $\mathrm{VO}_{2}$ torna-se mais dependente da $\mathrm{DO}_{2}$, e se eleva proporcionalmente às elevações da $\mathrm{DO}_{2}$, induzidas por intervenções terapêuticas. Assim, um aumento significativo do $\mathrm{VO}_{2}$, em resposta a um aumento da $\mathrm{DO}_{2}$, sugere hipoperfusão/hipoxia (dependência patológica) $)^{(4)}$. 


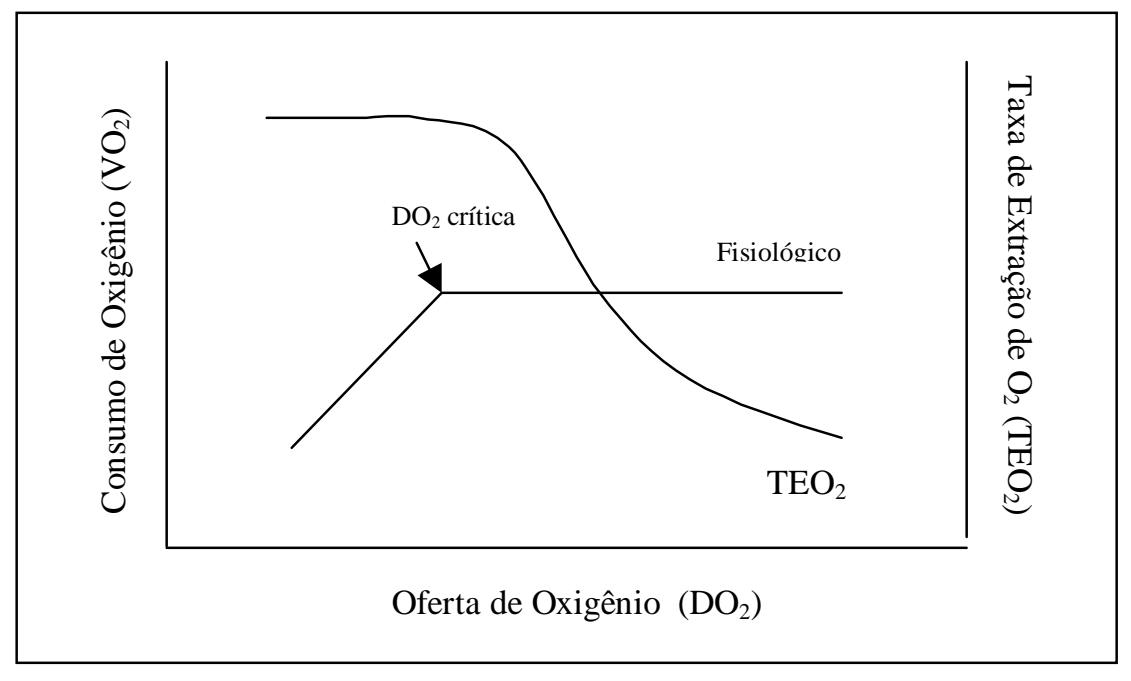

Figura 1: Relação entre oferta, consumo e taxa de extração de oxigênio.

Através da monitoração do $\mathrm{VO}_{2}$, frente às manipulações terapêuticas do $\mathrm{TO}_{2}$, é possível determinar a eventual adequação circulatória. Atualmente, a monitoração do paciente gravemente enfermo visa otimizar o transporte de oxigênio o "suficiente" para reduzir a acidose láctica e atender à demanda metabólica, em oposição à abordagem do passado onde se buscavam níveis supranormais de oferta de $\mathrm{O}_{2}{ }^{(4,5)}$.

\section{VARIÁVEIS CLÍNICAS QUE TRADUZEM PERFUSÃO TECIDUAL}

\subsection{Pressão arterial média (PAM) - pressão de perfusão (PP)}

A pressão arterial é o principal determinante da perfusão dos órgãos (associada ao débito cardíaco), uma vez que a pressão venosa central (PVC), em indivíduos sadios, é próxima de zero (PP = PAM - PVC). Desta forma, a manutenção de um nível adequado de PAM propicia, em geral, uma adequada perfusão orgânica. Discute-se, no entanto, qual o nível de PAM que se deve manter nos diferentes pacientes com síndrome do choque. Do ponto de vista prático, recorre-se às seguintes evidências:

a) quanto maior o tempo de hipotensão arterial, maior a possibilidade de desenvolvimento de disfunção orgânica;

b) o nível de hipotensão arterial é variável, no que concerne ao início da hipoperfusão tecidual; o estado cardiovascular prévio parece ser o principal determinante desse nível; c) a hipovolemia, em graus variados, contribui sobremaneira para o início e perpetuação da hipotensão arterial;

d) devem-se aferir os outros fatores que interferem na PAM, ou seja, contratilidade miocárdica e resistência vascular sistêmica, esta última calculada através das variáveis PAM, PVC e índice cardíaco (IC);

e) a mensuração da pressão arterial, pelo método não invasivo, perde confiabilidade à medida que a hipotensão é mais grave, da mesma forma, quando são utilizadas altas doses de drogas vasoativas ${ }^{(1)}$;

f) a própria análise da curva de pressão arterial pode fornecer importantes informações sobre o estado hemodinâmico, como, por exemplo, o estreitamento da base da curva indica que o paciente se encontra hipovolêmico.

Desta forma, preconiza-se:

a) durante a fase de ressuscitação do paciente em choque, pode ser necessário o uso de vasopressores até que se estabeleça adequada restauração da volemia, pois não se deve permitir hipotensão arterial importante (PAM < $65 \mathrm{~mm} \mathrm{Hg}$ ), por mais de $30 \mathrm{mi}-$ nutos;

b) lembrar que hipotensão arterial depende de dois fatores: débito cardíaco e resistência vascular sistêmica, assim, quando há disfunção miocárdica grave, esta pode manter a hipotensão arterial (choque cardiogênico), da mesma forma, a vasodilatação importante (choque distributivo);

c) após a restauração da volemia - definida como o ponto em que incrementos da pressão da artéria 
pulmonar ocluída não propiciam aumentos posteriores do débito cardíaco - deve-se indicar a infusão ou o aumento da dose de drogas vasoativas, caso estejam sendo utilizadas;

d) deve-se monitorar, de forma invasiva, todos os pacientes com instabilidade hemodinâmica que necessitem de drogas vasoativas;

e) finalmente, o nível ótimo de pressão arterial é avaliado clinicamente através de dois úteis parâmetros que são: débito urinário e frequiência cardíaca ${ }^{(6)}$.

Para finalizarmos, nunca deve ser esquecida a constante reavaliação clínica do paciente, pois a análise isolada das variáveis, fornecidas pela monitoração, propicia interpretações errôneas com condutas potencialmente ominosas.

\subsection{Pressão venosa central e pressão de arté- ria pulmonar}

As pressões venosa central (PVC) e de artéria pulmonar (PAP) possibilitam a interpretação das variáveis hemodinâmicas, auxiliando, de forma importante, o diagnóstico e o tratamento das diversas síndromes do choque.

A circulação cardiopulmonar é composta por vasos comunicantes, nos quais as pressões são transmitidas retrogradamente, onde a PVC reflete a pressão diastólica final do ventrículo direito (PDFVD), e a pressão da artéria pulmonar ocluída (PAPO), a pressão diastólica final do ventrículo esquerdo (PDFVE). Essas pressões podem ser aferidas, à beira do leito, através da monitoração com o cateter de artéria pulmonar (Swan-Ganz).

A PVC, que traduz o retorno venoso ao coração direito, se correlaciona com volemia, especialmente quando baixa, e representa hipovolemia. Quando normal ou elevada, perde seu valor, uma vez que é influenciada por doenças pulmonares, alteração da complacência do ventrículo direito e valvopatia tricúspide; então, não deve ser utilizada como parâmetro isolado de volemia.

A PVC, também, possibilita, através da comparação com a pressão de artéria pulmonar ocluída (PAPO), inferir sobre a disfunção cardíaca direita isolada ou secundária à disfunção ventrícular esquer- da, assim, como pode sugerir o diagnóstico de hipertensão arterial pulmonar.

Na presença de hipertensão pulmonar, é fundamental a análise da diferença entre a pressão diastólica da artéria pulmonar e a PAPO, uma vez que um gradiente inferior a $5 \mathrm{~mm} \mathrm{Hg}$ sugere hipertensão venocapilar, por disfunção valvar ou ventricular esquerda e, quando superior a $5 \mathrm{~mm} \mathrm{Hg}$, a hipertensão pulmonar resulta de alteração pulmonar primária, seja por mecanismos inflamatórios ou mesmo idiopática.

\subsection{Débito cardíaco (DC)}

O DC é o maior responsável pela oferta de oxigênio e nutrientes aos tecidos. A adequação desse parâmetro constitui medida indispensável no tratamento de pacientes graves.

A interpretação do DC deve ser feita de acordo com a demanda metabólica. Assim, não se pode inferir que um DC seja normal, sem os parâmetros de oxigenação tecidual. Um paciente, com insuficiência cardíaca e com quadro infeccioso grave, pode ter um DC dentro da normalidade (numericamente), entretanto ele pode ser insuficiente para uma dada demanda metabólica. Pode ser necessário elevar o DC, adequando-o às necessidades metabólicas. Em outras palavras, quando aumentamos o DC, temos que verificar se ocorre aumento no consumo celular de $\mathrm{O}_{2}$. A inalteração da $\mathrm{TEO}_{2}$, nesse contexto, confirma que houve aumento do consumo de $\mathrm{O}_{2}{ }^{(4)}$. Para facilitar o entendimento desta assertiva, poder-se-ia utilizar um gráfico que relaciona índice cardíaco (IC) com taxa de extração de oxigênio $\left(\mathrm{TEO}_{2}\right)$. $\mathrm{O}$ gráfico permite o cálculo, ou, pelo menos, a tendência de variação, do consumo de oxigênio $\left(\mathrm{VO}_{2}\right)$ (Figura 2).

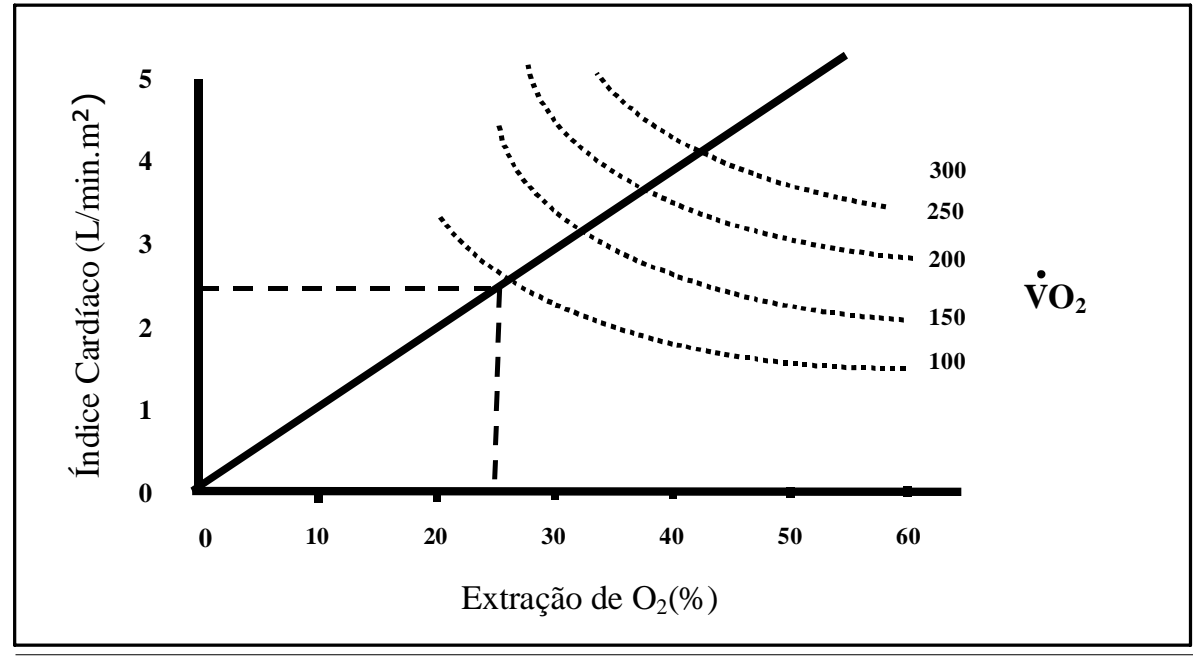

Figura 2: Relação entre índice cardíaco e taxa de extração de oxigênio. 
A forma mais simples de aferir quão adequado está o DC é a medida da $\mathrm{SvO}_{2}$. Partindo-se do princípio que, em indivíduos sadios, a $\mathrm{SvO}_{2}$ fica em torno de $70 \%$, medidas inferiores a esta podem indicar inadequação do DC.

Como regra geral, a interpretação do débito cardíaco deve obedecer a seguinte ordem:

a) indexar o DC, dividindo-o pela superfície corporal, obtendo-se, assim, o índice cardíaco;

b) verificar temperatura, hemoglobina e saturação arterial de oxigênio $\left(\mathrm{SaO}_{2}\right)$;

c) verificar $\mathrm{SvO}_{2}$;

d) avaliar condições que possam aumentar a demanda metabólica, como, por exemplo, agitação psicomotora, hipertermia, desconforto respiratório, crises convulsivas, etc.

e) por fim, pode-se utilizar o lactato sérico que, em geral, traduz o balanço entre oferta e consumo de oxigênio, especialmente nas fases iniciais de ressuscitação do choque.

\section{VARIÁVEIS LABORATORIAIS QUE TRADUZEM PERFUSÃO TECIDUAL}

\subsection{Saturação venosa mista de oxigênio - $\mathrm{SvO}_{2}$}

A monitoração da $\mathrm{SvO}_{2}$ permite avaliar a relação entre oferta e consumo sistêmicos de oxigênio. Grosseiramente, quando normal (65-75\%), indica uma relação adequada. Quando inferior a $65 \%$, é característico o aumento da $\mathrm{TEO}_{2}$, e pode indicar limitação da $\mathrm{DO}_{2}$ (devido à inadequação do DC, anemia, hipoxemia) ou aumento da demanda metabólica. Por outro lado, $\mathrm{SvO}_{2}$ superior a $75 \%$ indica estado de hiperfluxo, onde há aumento na relação oferta/consumo, com redução da $\mathrm{TEO}_{2}$; essa situação pode ser vista na sepse, cirrose, pancreatite, politrauma, etc ${ }^{(1)}$.

No tratamento de pacientes com síndrome de choque, a $\mathrm{SvO}_{2}$ deve ser mantida $>65 \%$, já que valores inferiores a este, em geral, estão claramente associados ao comprometimento da $\mathrm{DO}_{2}$. Isso pode ser conseguido através da infusão de líquidos, inotrópicos, transfusão de sangue, suporte ventilatório ou, nos casos de aumento da demanda, através do controle de agitação, convulsões, febre, etc ${ }^{(1)}$.

Quando a $\mathrm{SvO}_{2}$ se mantém normal ou elevada, em pacientes gravemente enfermos, a mesma perde a confiabilidade em indicar o estado perfusional, caracterizando apenas um estado hiperdinâmico, pois esta é uma média global, podendo não indicar graves desequilíbrios entre a oferta e consumo de $\mathrm{O}_{2}$ em nível regional.

\subsection{Lactato}

Apesar da complexidade das vias bioquímicas, relacionadas à cinética do lactato sangüíneo, este é melhor índice prognóstico, em pacientes graves, do que as variáveis derivadas da oxigenação tecidual $-\mathrm{DO}_{2} \mathrm{e}$ $\mathrm{VO}_{2}{ }^{(7)}$.

É imperativo uma correta interpretação dos níveis séricos de lactato, para elucidar os mecanismos fisiopatológicos que produziram sua elevação e as vias nas quais poder-se-ia interferir, em tais mecanismos.

Três tópicos devem ser discutidos para um melhor entendimento:

a) Fisiologia do lactato - o lactato é o produto final da glicólise anaeróbia, produzido, normalmente, numa taxa de $1 \mathrm{mmol} / \mathrm{kg} / \mathrm{h}$, especialmente no músculo esquelético, intestino, cérebro e eritrócitos. O lactato gerado nesses tecidos pode ser extraído pelo fígado e convertido em glicose (via gliconeogênese) ou pode ser utilizado como substrato primário para oxidação (fonte de energia). Figura 3. A reação para a glicólise anaeróbia é a seguinte:

Glicose $+2 \mathrm{ATP}+2 \mathrm{H}_{2} \mathrm{PO}_{4} \Rightarrow 2$ Lactato $+2 \mathrm{ADP}+2 \mathrm{H}_{2} \mathrm{O}$

ATP: Trifosfato de adenosina; ADP: Adenosina; $\mathrm{H}_{2} \mathrm{PO}_{4}$ : Ácido fosfórico; $\mathrm{H}_{2} \mathrm{O}$ : Água

A reação produz lactato, não ácido láctico. É necessária a hidrólise do ATP para fornecer íons de hidrogênio para converter lactato em ácido láctico ${ }^{(7)}$.

b) Fisiopatologia da hiperlactatemia - a concentração normal de lactato no sangue é inferior a 2 $\mathrm{mmol} / \mathrm{L}$, em repouso, e até $5 \mathrm{mmol} / \mathrm{L}$ durante o exercício. Inúmeras condições podem propiciar hiperlactatemia, incluindo: deprivação de oxigênio (hipoxia tecidual), sepse, infusão de adrenalina, deficiência de tiamina, alcalose (metabólica ou respiratória), disfunção hepática e intoxicação por nitroprussiato ${ }^{(8)}$ (Figura 3 ).

A hipoxia tecidual aumenta os níveis de lactato por aumentar a glicólise anaeróbia (para manter a produção energética celular mais próxima do normal). A síndrome de choque é a grande responsável por tal situação. Lembrar que a intoxicação por nitroprussiato (cianeto) também eleva o lactato devido à hipoxia tecidual.

A sepse pode causar hiperlactatemia por vários motivos: a) hipoxia tecidual (principalmente na fase inicial do choque séptico); b) inibição da enzima piruvato desidrogenase (PDH)- a qual inicia a oxidação do piruvato na mitocôndria; c) glicólise aumentada, uma vez que aumenta a oferta de substrato (piruvato), saturando a enzima PDH. Disfunção hepática também 


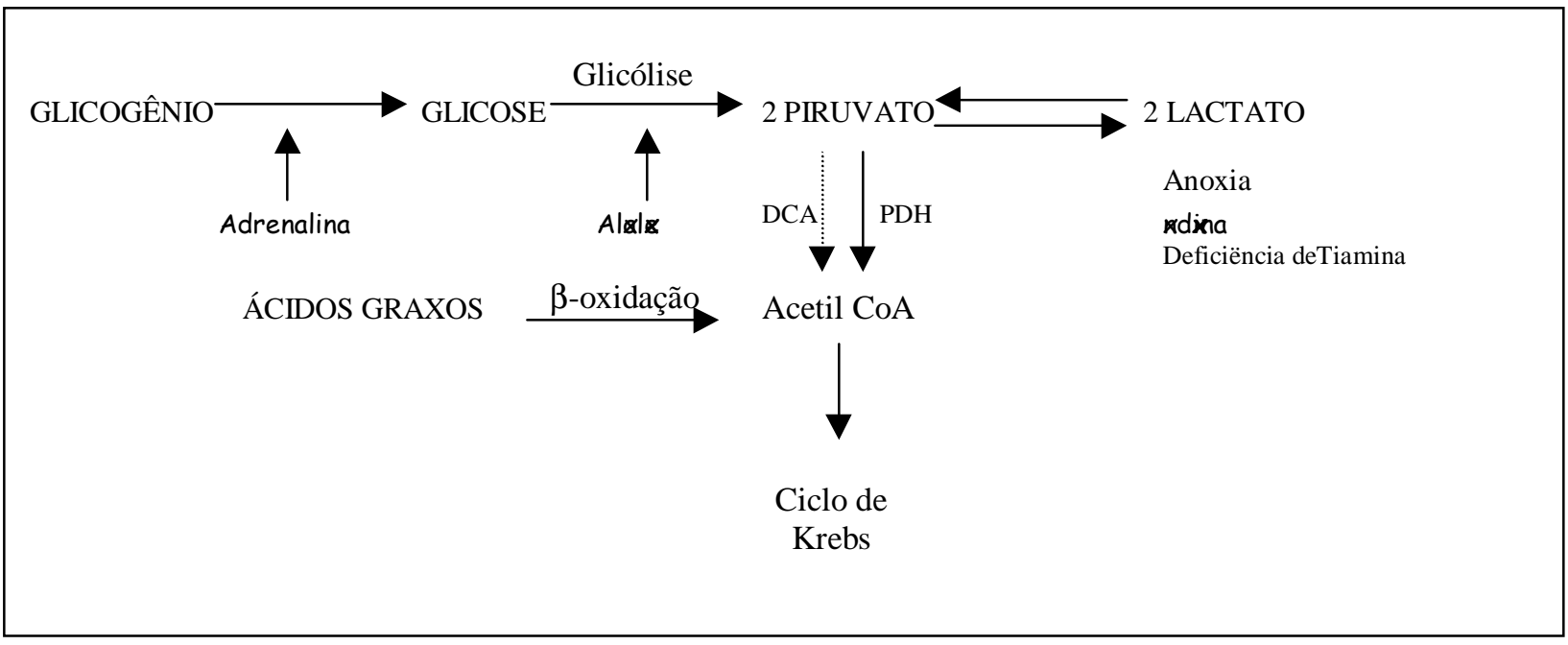

Figura 3: Metabolismo e fisiopatolgia do lactato.

colabora para hiperlactatemia nos pacientes sépticos, por redução da depuração de lactato. Estes dois últimos fatores explicam a hiperlactatemia na sepse, mesmo na ausência de hipoxia tecidual. A infusão de adrenalina também aumenta a glicólise.

A tiamina serve como cofator para a piruvatodesidrogenase, portanto, sua deficiência pode ser acompanhada de hiperlactatemia. A alcalose intracelular aumenta a atividade de enzimas $\mathrm{pH}$-dependentes, na via glicolítica, que promovem a produção de lactato. Eis mais um motivo a ser considerado no sentido de se evitar a terapêutica com álcalis durante hiperlactatemia.

Finalmente, hiperlactatemia secundária à disfunção hepática isolada não é uma causa freqüente.

Assim, lactato sérico aumentado não significa necessariamente hipoxia tecidual.

c) Interpretação clínica da hiperlactatemia - o principal mecanismo de hiperlactatemia, nos pacientes com choque, é a hipoxia tecidual. No entanto, devemos dividir a síndrome do choque em duas categorias: a) síndromes de baixo fluxo (débito cardíaco deprimido - choque cardiogênico, hipovolêmico e obstrutivo); b) síndromes com alto fluxo (débito cardíaco elevado - choque séptico, anafilático e secundário à insuficiência adrenal aguda).

Nas síndromes de baixo fluxo, a hiperlactatemia é por hipoxia tecidual. Nesse caso, estão presentes achados que traduzem baixa oferta de oxigênio aos tecidos. Observam-se sinais clínicos de baixa perfusão tecidual, como diminuição do nível de consciência (por vezes agitação), da diurese, do enchimento capilar e, a posteriori, hipotensão arterial. Do ponto de vista laboratorial, encontra-se aumento do déficit de base, da diferença venoarterial de oxigênio e de dióxido de carbono, bem como diminuição da $\mathrm{SvO}_{2}$, que obedece um paralelismo com a queda do débito cardíaco. Ainda nessa fase, observa-se uma dependência estrita do consumo em relação à oferta de oxigênio. A hiperlactatemia persistente, nesses pacientes é sinal de mau prognóstico devido ao vínculo fisiopatológico entre hiperlactatemia e hipoxia tecidual persistente um dos "motores" da disfunção de múltiplos órgãos ${ }^{(7)}$.

Nas síndromes de alto fluxo, em virtude da interação de vários componentes fisiopatológicos, propiciando hiperlactatemia, a interpretação clínica dos níveis de lactato merece alguns cuidados. Nas fases iniciais da ressuscitação, possivelmente, encontraríamos hipoxia tecidual e dependência do consumo em relação à oferta de oxigênio. Assim, nas primeiras 4872 horas, o lactato sérico elevado é um sinal de mau prognóstico. Em contrapartida, após a fase, em que o débito cardíaco foi restaurado, a saturação venosa mista de oxigênio supera $65 \%$ e, habitualmente, o comportamento da oferta e do consumo de oxigênio são imprevisíveis, o lactato sérico pode ser normal, mesmo na vigência de disfunção orgânica galopante. Em outras palavras, o poder prognóstico do nível sérico do lactato (uma vez que ele pode ser normal), perde em acurácia. No entanto, independentemente do mecanismo preponderante da hiperlactatemia (hipoxia tecidual, inibição da piruvato desidrogenase, hipermetabolismo ou diminuição da depuração hepática), a mesma sinaliza atividade patológica. Assim, nesses pacientes, o nível sérico de lactato é especialmente útil nas fases inicias, devendo ser analisado com cautela a posteriori na evolução clínica dos mesmos. 
Algumas regras podem ser usadas para interpretação dos níveis de lactato:

I) a mensuração sérica do lactato deve estar disponível em todas as unidades de terapia intensiva e constar na avaliação rotineira dos pacientes gravemente enfermos;

II) todos os intensivistas devem estar familiarizados com a cinética do lactato;

III) o valor isolado do lactato sérico é de pouca utilidade, mas sua evolução, ao longo do tempo, é de maior utilidade clinica;

IV) níveis séricos de lactato não devem substituir a avaliação clínica, e o tratamento não deve ser guiado unicamente pelos níveis séricos do lactato; a combinação dessa variável com outras (pCO2gap, por exemplo) pode ser mais informativa;

V) acidose láctica traduz uma anormalidade de base e não é por si só uma alteração fisiopatológica a ser revertida;

VI) apesar das limitações, na interpretação dos níveis séricos do lactato, em pacientes sépticos, a hiperlactatemia sugere a presença de importantes alterações metabólicas e, em qualquer paciente grave, deve ser encarada como sinal de mau prognóstico.

\subsection{Tonometria gástrica - Capnografia regio- nal}

Durante anos, as variáveis sistêmicas de oxigenação tecidual - $\mathrm{DO}_{2}$ e $\mathrm{VO}_{2}$ - foram destacadas dentro do campo fisiopatológico e terapêutico do paciente gravemente enfermo, propagando-se a idéia de que valores "supranormais" poderiam satisfazer a alta demanda metabólica, reduzindo a incidência da disfunção de múltiplos órgãos e, assim, a taxa de mortalidade. No entanto, novas evidências questionam essas prerrogativas e apontam para um melhor entendimento da distribuição do fluxo sangüíneo nessa população específica $^{(9)}$.

Anteriormente, demonstramos a utilidade da mensuração do lactato sérico nos pacientes com síndrome do choque, destacando que, em algumas condições clínicas, apresenta relação estrita com hipoxia tecidual sistêmica. No entanto, o lactato sérico é a média ponderada de vários locais do organismo onde a relação entre oferta e consumo de oxigênio varia. Assim, torna-se difícil interpretar os níveis do lactato, principalmente quando normais, na vigência de disfunções orgânicas, onde a perfusão tecidual é absolutamente heterogênea.
Sabe-se que, especialmente em pacientes sépticos, há distribuição irregular do DC e que as alterações induzidas por drogas vasoativas, em nível sistêmico, não encontram, necessariamente, correspondência em nível regional. Especificamente, o território esplâncnico, investigado em estudos clínicos, apresenta perfis hemodinâmicos distintos daqueles das variáveis sistêmicas ${ }^{(10)}$.

Com o advento da tonometria gástrica e de seu melhor entendimento fisiológico e fisiopatológico (produção e depuração do $\mathrm{CO}_{2}$ tecidual e sua relação com fluxo), pode-se verificar, à beira do leito, o comportamento do fluxo da mucosa gástrica, trazendo a conceituação de distribuição do fluxo sangüíneo inter e intra-órgãos.

A tonometria gástrica permite a mensuração da $\mathrm{pCO}_{2}$ da mucosa gástrica que tem íntima relação com fluxo e com hipoxia tecidual. $\mathrm{O} \mathrm{CO}_{2}$ tecidual só aumenta, de forma patológica, quando não há relação linear entre produção e fluxo ${ }^{(11,12)}$. Dessa forma, qualquer queda da perfusão tecidual, nesse território, seria sinalizada por um aumento do $\mathrm{CO}_{2}$ tecidual (avaliado pela tonometria). Assim, utiliza-se, hoje, a mensuração da $\mathrm{pCO}_{2}$ da mucosa gástrica como indicativo de fluxo. Para descartar a influência da ventilação alveolar sobre esta $\mathrm{pCO}_{2}$ tecidual, utiliza-se o $\mathrm{pCO}_{2}$-gap $\left(\mathrm{pCO}_{2} \text { gástrico - } \mathrm{pCO}_{2} \text { arterial }\right)^{(9)}$. Um gradiente elevado, acima de $10 \mathrm{~mm} \mathrm{Hg}$, indica diminuição da perfusão da mucosa gástrica, o que, em vários estudos, apresentou correlação com mau prognóstico.

Assim, impõe-se, hoje, uma reavaliação da monitoração das variáveis de perfusão tecidual. Oferta e consumo de oxigênio são variáveis importantes; no entanto, principalmente a oferta de oxigênio apresenta pouca relação com prognóstico. Da mesma forma, os níveis séricos de lactato traduzem o equilíbrio sistêmico entre oferta e consumo, e, nos pacientes com importante distúrbio perfusional, podem traduzir alterações metabólicas outras que não hipoxia tecidual. Por fim, a monitoração da $\mathrm{pCO}_{2}$ da mucosa gástrica, que traduz fluxo regional, pode ser mais acurada como marcador prognóstico ${ }^{(13)}$.

\subsection{Relação entre lactato sérico e tonometria gástrica}

A interpretação conjunta dessas duas variáveis, associada às outras mensurações hemodinâmicas e de oxigenação tecidual, permite inferências e até tomadas de decisões (Figura 4). 


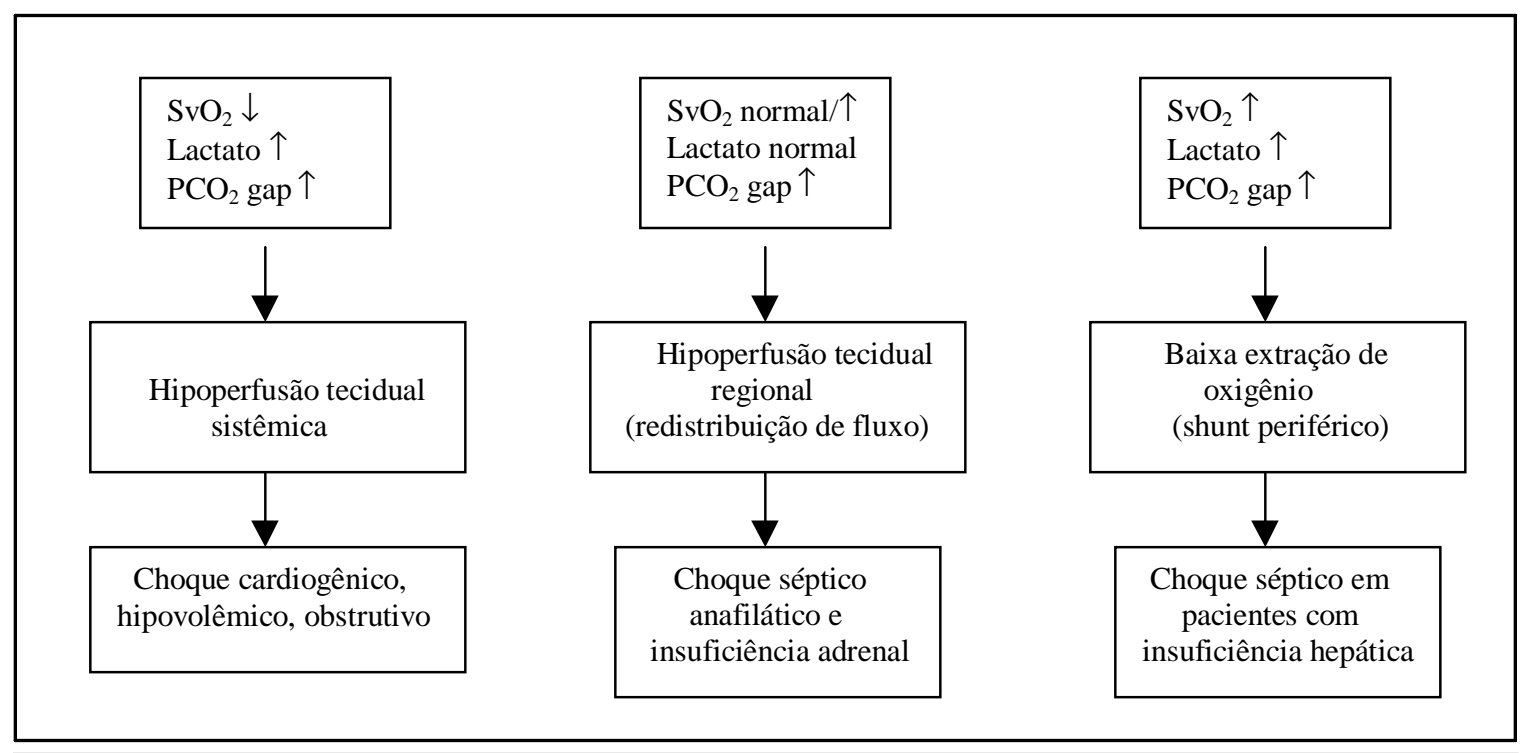

Figura 4: Algoritmo de avaliação da perfusão tecidual em pacientes com síndrome do choque

O processo de estabilização hemodinâmica e oxigenação tecidual obedece a uma ordem de prioridades, as quais visam manter o metabolismo celular. Do ponto de vista prático, o processo de ressuscitação segue as seguintes prioridades:

I) pressão arterial média acima de $65 \mathrm{~mm} \mathrm{Hg}$;

II) diurese acima de $1 \mathrm{ml} / \mathrm{kg} / \mathrm{h}$;

III) débito cardíaco suficiente para manter uma $\mathrm{SvO}_{2}$ acima de $65 \%$;

IV) lactato sérico inferior a $2 \mathrm{mmol} / \mathrm{L}$;

V) e, ainda, necessitando de maiores evidências, $\mathrm{pCO}_{2}$-gap inferior a $10 \mathrm{~mm} \mathrm{Hg}$.

Como já destacado, os níveis séricos de lactato traduzem uma média ponderada de diversos perfis metabólicos e perfusionais e não indicam qual setor estaria sofrendo a mais grave alteração perfusional. Indubitavelmente, o $\mathrm{pCO}_{2}$-gap traduz um perfil hemodinâmico regional e, assim, poder-se-iam encontrar pacientes com níveis séricos de lactato normais com $\mathrm{pCO}_{2}$-gap elevado (redistribuição de fluxo sem alterar sobremaneira a produção de lactato). O inverso é improvável. O raciocínio sugerido é de que, uma vez restauradas as variáveis sistêmicas, dever-se-ia abordar os diferentes fluxos regionais.

Sabe-se que níveis séricos, persistentemente elevados, de lactato são indicativos de mau prognóstico na maioria dos pacientes com choque. Sabe-se, também, em amostra ainda restrita, que a manutenção de uma acidose de mucosa gástrica (elevado $\mathrm{pCO}_{2}$-gap) está correlacionada também à evolução desfavorável.
No entanto, especialmente em pacientes sépticos, lactato sérico normal (principalmente no período pósressuscitação) não garante evolução favorável. Nesses pacientes, e principalmente no período da evolução clínica, necessitar-se-ia um outro guia perfusional e, quiçá, terapêutico. Alguns dados de literatura sugerem, na verdade, a combinação das duas variáveis (lactato e $\mathrm{pCO}_{2}$-gap) para aumentar o poder prognóstico especialmente na população séptica.

Com as evidências disponíveis pode-se dizer que:

1. não há, necessariamente, relação entre níveis séricos de lactato e $\mathrm{pCO}_{2}$-gap;

2. o lactato sérico deve ser um guia prognóstico e terapêutico, especialmente em pacientes com baixo débito e nas fases iniciais do choque séptico;

3. o intensivista deve estar familiarizado com as variáveis que interferem na distribuição de fluxo nesses pacientes, bem como a real interpretação da mensuração do $\mathrm{pCO}_{2}$ de mucosa gástrica como indicador de fluxo regional;

4. o $\mathrm{pCO}_{2}$-gap parece ter um importante valor prognóstico; sua utilização como guia terapêutico carece de estudos adicionais ${ }^{(6,9)}$.

\section{DESTAQUE}

Finalmente, cabe ressaltar, mais uma vez, a importância da ressuscitação adequada de pacientes com síndrome do choque, visando diminuir o desequilíbrio entre oferta e consumo de $\mathrm{O}_{2}$, reduzindo a incidência 
de disfunção orgânica e, conseqüentemente, a alta morbimortalidade associada a tal condição. Para atingir tal meta, é necessário uma monitoração apropriada das variáveis clínicas (PAM, diurese, nível de consciência, coloração e temperatura da pele) e laboratoriais (níveis séricos de lactato, $\mathrm{SvO}_{2}$ e $\mathrm{pCO}_{2}$ gap) que traduzem a perfusão tecidual, orientando as inter- venções terapêuticas. Deve ser lembrado que é de extrema valia a avaliação seqüencial e em conjunto dessas variáveis, destacando que, mesmo quando normalizadas as variáveis sistêmicas de oxigenação, graves distúrbios perfusionais regionais ainda podem existir, sendo necessário recorrer à monitoração regional.

SILVA E; GARRIDO AG \& ASSUNÇÃO MSC. Tissue perfusion assesment in shock. Medicina, Ribeirão Preto, 34: 27-35, jan./march 2001.

ABSTRACT: Although new technologies have emerged and the tissue perfusion assessment has improved, shock remains with a high mortality ratio. Multiple organ dysfunction syndrome (MODS) due to tissue hypoperfusion is the best reason to explain this high mortality ratio in these patients. Hence, tissue perfusion assessment has the pivotal role in the shocked patient evaluation, because some therapeutic interventions can be performed.

In this review, will be highlighted the main clinic signs and laboratories findings observed in hypoperfusion syndromes, including oxygen transport, oxygen delivery, oxygen consumption, oxygen extraction ratio, oxygen mixed venous saturation, arterial lactate end gastric-arterial $\mathrm{CO}_{2}$ gradient. These concepts are very important to understand and choose the best intervention for breaking events that are responsible for MODS development and death.

The goals of resuscitation are also provided including mean arterial pressure above $65 \mathrm{~mm}$ $\mathrm{Hg}$, mixed venous oxygen saturation above $65 \%$, and lactate levels below $2 \mathrm{mMol} / \mathrm{L}$. However, regional hypoperfusion can persist despite of restoring global hemodynamic variables. Hence, gastric-mucosal PCO2 could be a therapy-guide.

UNITERMS: Shock. Tissue Perfusion. Tonometry. Lactates. Oxygen Transfer.

\section{REFERÊNCIAS BIBLIOGRÁFICAS}

1 - TASK FORCE OF THE AMERICAN COLLEGE OF CRITICAL CARE MEDICINE. Practice parameters for hemodynamic support of sepsis in adult patients in sepsis. Crit Care Med 27:639-660, 1999.

2 - BAIGORRI F\& RUSSEL J A. Oferta de oxigênio na doença crítica. Clín Terapia Intens 4: 959-983, 1996.

3 - DANTZKER D R. Pulmonary gas exchange. In: DANTZKER DR \& SCHARF SM. Cardiopulmonary critical care, $3^{\text {rd }}$ edition, WB Sauders, Philadelphia, p. 29 - 49, 1998.

4 - VINCENT JL. Determinação da oferta de oxigênio e do consumo do oxigênio versus índice cardíaco e taxa de extração do oxigênio. Clín Terapia Intens 4: 985-996, 1996

5 - GATTINONI L; BRAZZI L; PELOSI P; LATINI R; TOGNONI G; PESENTI A \& FUMAGALLI R. For the $\mathrm{SvO}_{2}$ collaborative group a trial of goal-oriented hemodynamic therapy in critically ill patients. N Engl J Med 333: 1025-1032, 1995

6 - REINHART K; SAKKA S G\& MEIER-HELLMANN AA. Haemodynamic management of a patient with septic shock. Eur J Anaesthesiol 17: 6-17, 2000.

7 - VINCENT JL. Lactate levels in critically ill patients. Acta Anaesthesiol Scand 107:261-266, 1995. Suppl.
8 - MISOCK BA \& FALK JL. Lactic acidosis in critical illness. Crit Care Med 20:80-93, 1992.

9 - SIEGEMUND M; VAN BOMMEL J \& INCE C. Assesssment of regional tissue oxygenation. Intens Care Med 25:10441060,1999.

10 - ROUKONEN E; TAKALA J \& KARI A. Regional blood flow and oxygen transport in septic shock. Crit Care Med 21:1296-1303, 1993.

11 - CRETEUR J; DE BACKER D \& VINCENT JL. Does gastric tonometry monitor splanchnic perfusion? Crit Care Med 27:2480-2484, 1999

12 - SILVA E; DE BACKER D; CRETEUR J \& VINCENT JL. Effect of vasoactive drugs on gastric intramucosal pH. Crit Care Med 26:1749-1758, 1998.

13 - FRIEDMAN G; BERLOT G; KAHN RJ \& VINCENT JL. Combined measurements of blood lactate concentrations and gastric intramucosal pH in patients with severe sepsis. Crit Care Med 23:1184-1193, 1995.

\section{Recebido para publicação em 06/07/2000}

Aprovado para publicação em 19/01/2001 